\title{
Transposition of the Levator Muscle and its Reinnervation
}

\author{
J.-M. LEMAGNE \\ Brussels, Belgium
}

\begin{abstract}
Summary
The frontalis transposition of the levator muscle changes the motor innervation of the muscle from the third nerve to the facial nerve. This contributes together with the sling effect of the transfer to achieve a satisfactory result in the treatment of neurogenic ptosis as in the ptosis of the Marcus Gunn's phenomenon.
\end{abstract}

A muscular transposition allows the modification the vector of the contraction and/or the change of the motor innervation of the grafted muscle. When applied to the frontalis transfer of the levator palpebral muscle, the goal of the transposition is to replace a deficient third nerve motor control with a more satisfactory frontal nerve control.

A successful muscle transfer requires several criteria, including regeneration of the fibres lost during the procedure and the reinnervation of the grafted muscle.

The mechanisms of muscular regeneration are still partly speculative but involve the satellite cells of the muscle. These cells are precursors of the fibres and under certain circumstances such as an ischaemic necrosis of the muscular fibres, differentiate into new fibres. ${ }^{1}$

The reinnervation of a denervated muscle can be accomplished either by neural neurotisation or by muscular neurotisation. ${ }^{2}$

The neural neurotisation is obtained either by implantation of a motor nerve in the muscle or by suture of a motor nerve to the nerve pedicle of the muscle.

The muscular neurotisation requires contact with a healthy muscle. Following this con- tact the motor nerve fibres of the innervated muscle develop collateral neural ramifications that invade the paralysed muscle. Several weeks after their penetration into the denervated muscle, the new axons develop synaptic connections that activate the reinnervated muscle. ${ }^{3}$ Muscular neurotisation is most useful as when a proximal motor nerve stump is not available as in the technique of neurogenic ptosis.

\section{Surgical Technique}

The levator muscle is approached by an incision under the eyebrow followed by dissection of the orbicularis muscle, the septum and the preaponeurotic fat (Fig. 1). The levator muscle is severed as far back as possible into the orbit. The distal part of the muscle is pulled out of the orbit. A non-absorbable suture is placed through the plane of the section.

Through a second incision above the eyebrow the vertical fibres of the frontalis muscle are dissected and their aponeurosis is removed. A blunt dissection makes a tunnel between the orbicularis muscle and the periosteum in order to create a connection between the two incisions. The levator muscle

From the Department of Ophthalmology, Cliniques Universitaires St Luc, Université Catholique de Louvain, Brussels.

Correspondence to Dr. Lemagne, Cliniques Universitaires St Luc, Av, Hippocrate 10, B-1200 Brussels, Belgium. 


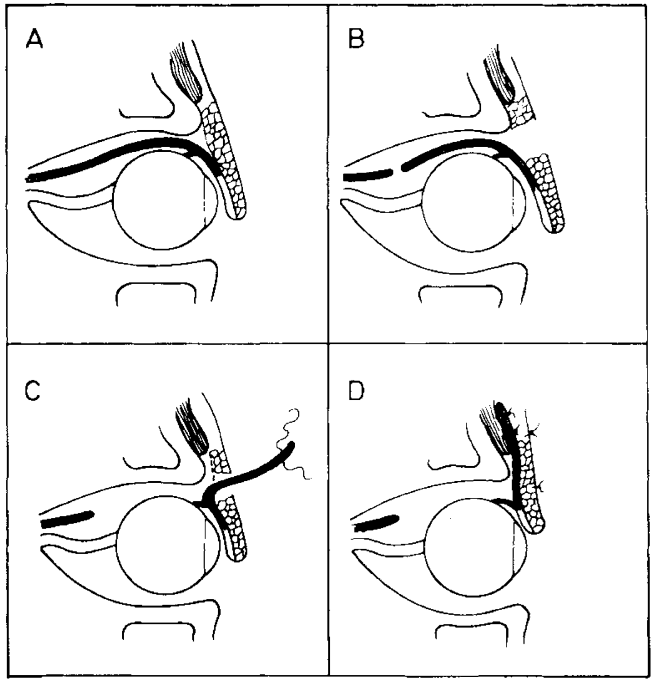

Fig. 1. Diagram of the surgical technique for frontalis transposition of the levator muscle.

is inserted through the tunnel and sutured to the vertical fibres of the frontalis muscle. The tension of the levator must be sufficient to pull the upper lid margin up to the corneoscleral limbus. The wounds are closed layer by layer.

Any regional ptosis remaining sixth months after the transfer is corrected by an anterior approach levator resection.

\section{Results}

In cynomolgus monkeys the upper lid resumes its original position after a variable number of weeks of postoperative ptosis.

At that time the electromyographic recording of the levator muscle shows a reinnervation activity concommitant with the contraction of the frontalis muscle and the lid motion.

Histochemistry of the transposed muscle reveals the loss of the typical pattern of extraocular muscles (granular fibres, coarse fibres, and fine fibres according to the classification proposed by Durston $)^{4}$ and their replacement by fibres with the characteristics of limb muscles, similar to those of the frontalis muscle. $^{5}$

As the metabolic differentiation of a muscle is dependant on its innervation and is modified when the type of innervation changes, ${ }^{6}$ the metabolic shift of the transposed levator as well as its EMG activity indicates that the levator has come under the control of the facial nerve after muscular neurotisation from the frontalis muscle, which is an agonist of the levator. This partly preserves the levator function and contributes with the sling effect to achieve a normal or nearly normal upper lid level.

\section{Clinical applications}

The frontalis transfer of the levator muscle can be successfully used in the treatment of severe ptosis with Marcus Gunn's phenomenon. Section of the levator muscle involves no sacrifice because its abnormal function must be suppressed, ${ }^{7}$ and the use of the sectioned muscle for supporting the lid not only avoids the implantation of prosthetic material or fascia lata but also retains a certain amount of levator function.

\section{Case Report 1}

A 13-year-old girl with a severe ptosis and Marcus Gunn's phenomenon was operated on under general anesthaesia. (Fig 2). The ptosis was complete during the first month following the frontalis transfer of the levator. Then it progressively decreased to attain a stable $6 \mathrm{~mm}$ lid fissure at 6 months postoperatively. The synkinetic lid motion completely disappeared.

The residual ptosis was corrected by a $22 \mathrm{~mm}$ anterior approach levator resection.

This 2 step surgery achieved an almost symmetrical lid fissure with little lid lag and the disappearance of the Marcus Gunn's phenomenon.

Two other Marcus Gunn's ptosis patients were operated on with similar results.

The levator transfer was also used but with less success to a patient suffering from a acquired complete third nerve palsy.

\section{Case Report 2}

A 38-year-old patient suffered from a third nerve paralysis following blunt head trauma for 8 months (Fig. 3).

Two months after transfer the lid opening progressively increased and at 6 months the patient was able to open the lid up to $6 \mathrm{~mm}$. This made the diplopia symptomatic. An attempt to correct the paralytic strabismus failed to relieve the diplopia. Because of this persisting diplopia the patient voluntarily keeps his eye closed.

\section{Conclusions}

The levator transposition technique completed by a secondary levator resection has 


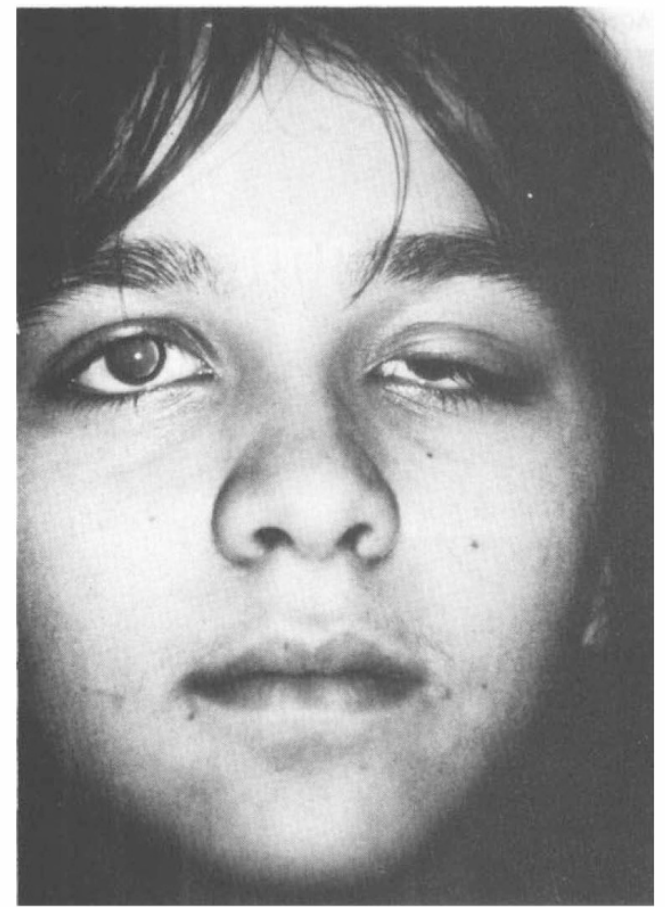

$\mathbf{a}$

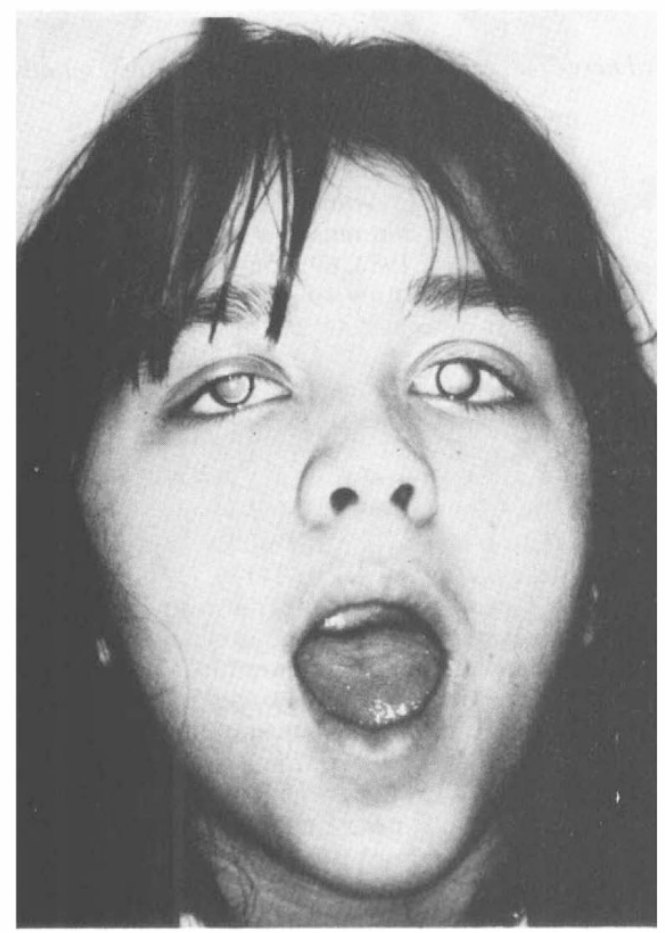

b

Fig. 2. A 13-year-old girl with severe ptosis and Marcus Gunn's phenomenon. (A) Primary position (B); synkinetic motion $(C) ; 6$ months following the levator transposition (D); final result following an additional $22 \mathrm{~mm}$ levator resection (E); disappearance of the Marcus Gunn's phenomenon.

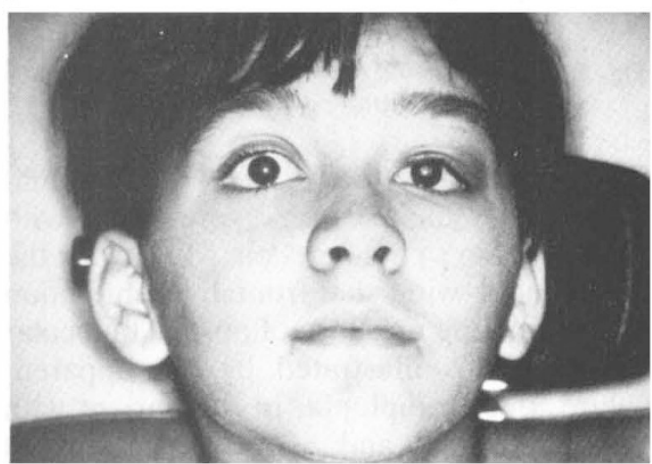

d

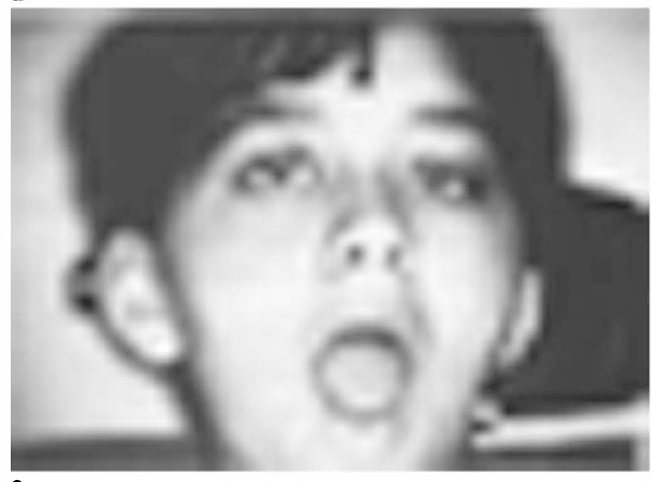

e

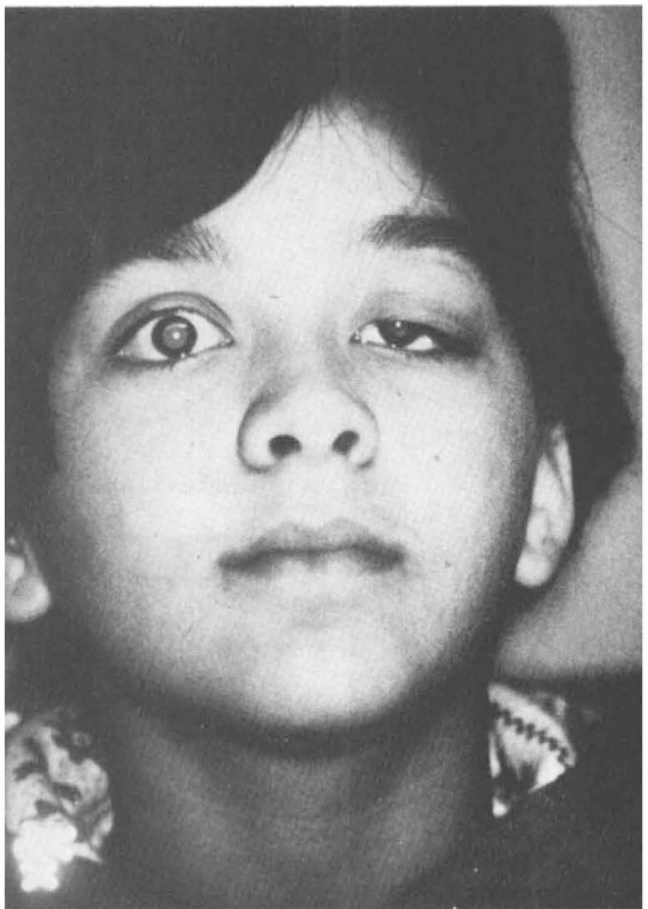




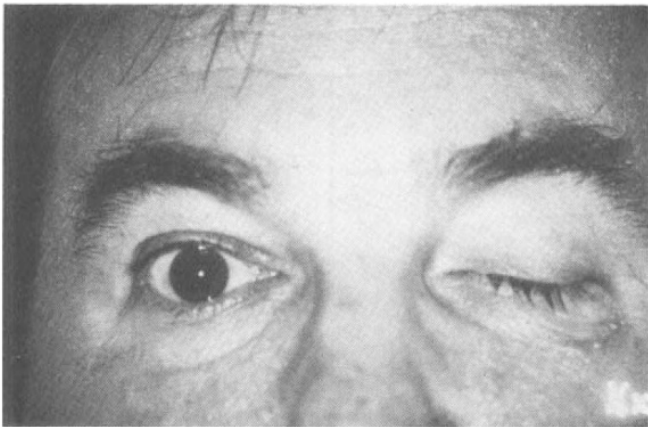

a

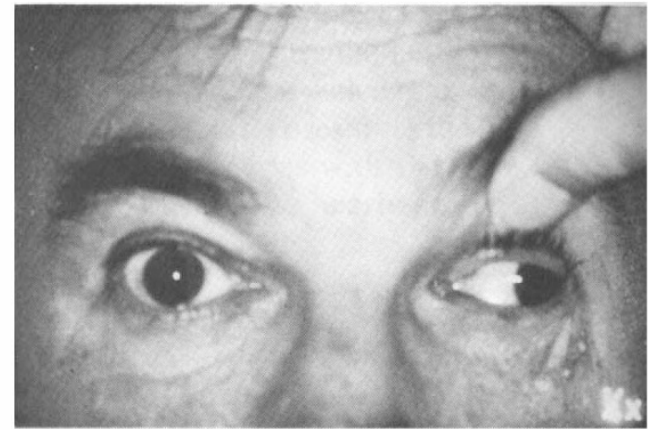

b

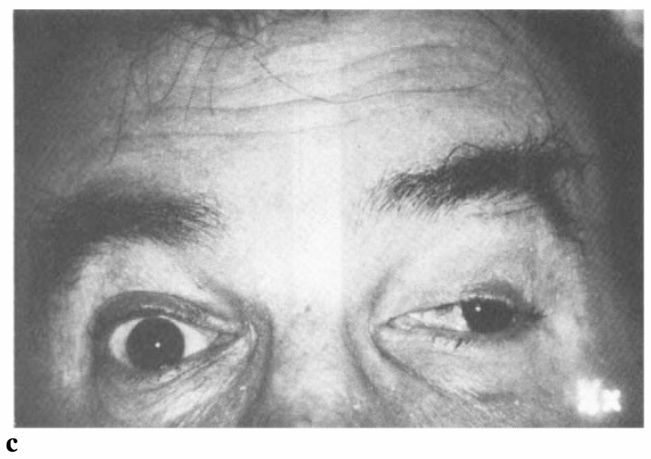

Fig. 3. A 38-year-old man with a 8 months traumatic third nerve palsy $(A, B) ;$ a 6 mm lid opening at 6 months following the levator transposition.

proved to be an effective treatment in a limited number of cases of severe ptosis with Marcus Gunn's phenomenon. Meanwhile the lid opening with the frontalis contraction depends on the presence of normal binocular vision: this is illustrated by the apparent failure, due to diplopia, in the patient with third nerve palsy and, as for a conventional frontalis sling, it can be assumed that a lack of stimulus to open the lid will result from amblyopia.

\section{References}

${ }^{1}$ Plaghki L: Régénération et myogenése du muscle strié. J Physiol (Paris) 1985, 80: 51-110.

${ }^{2}$ Frey M, Gruber H, Holle J, Freilinger G: An experi- mental comparison of the different kinds of muscle reinnervation: nerve suture, nerve implantation, and muscular neurotisation. Plast Reconstr Surg 1982, 69: 656-67.

${ }^{3}$ Brown MC: Sprouting of motor nerves in adult muscles: a recapitulation of ontogeny. Trends Neurosci 1984, 10-14.

${ }^{4}$ Durston JHJ: Histochemistry of primate extraocular muscle and the changes of denervation. $\mathrm{Br} \mathrm{J}$ Ophthalmol 1974, 58: 193-216.

${ }^{5}$ Lemagne J-M, Brucher, JM, Michiels J: Clinical, biochemical and histological results of a levator muscle transposition for ptosis in Cynomolgus monkeys. Orbit 1985, 1: 141-6.

${ }^{6}$ Karpati $G$ and Engel WK: Transformation of the histochemical profile of skeletal muscle by 'foreign innervation'. Nature 1967, 215: 1509-10.

${ }^{7}$ Bullock JD: Marcus Gunn jaw-winking ptosis: Classification and surgical management. J Pediatr Ophthalmol 1980, 17: 375-9. 